\title{
Potentiation of the hypoxic ventilatory response by one day of hyperoxia in neonatal rats
}

\author{
Jeffrey C. Roeser, Diane G. Brackett, Eliza S. van Heerden, Kristen M. Young, and Ryan W. \\ Bavis \\ Department of Biology, Bates College, Lewiston, ME 04240
}

\begin{abstract}
The $\mathrm{O}_{2}$ sensitivity of the neonatal rat carotid body is increased after one day in moderate hyperoxia $\left(60 \% \mathrm{O}_{2}\right)$ (Donnelly et al., Respir. Physiol. Neurobiol. 168: 189-197, 2009). We investigated whether this enhanced peripheral chemosensitivity increases the hypoxic ventilatory response (HVR) and tested the hypothesis that this plasticity is mediated by the superoxide anion. Neonatal rats ( $7 \mathrm{~d}$ old $)$ were injected with saline or MnTMPyP, a superoxide scavenger, and placed into $60 \% \mathrm{O}_{2}$ for $23-28 \mathrm{~h}$. Baseline ventilation was reduced and the acute HVR $\left(12 \% \mathrm{O}_{2}\right)$ was enhanced in hyperoxia-treated rats relative to age-matched controls; MnTMPyP did not block these effects. An additional group of rats was studied after only $30 \mathrm{~min}$ in $60 \% \mathrm{O}_{2}$. This shorter exposure had no effect on normoxic ventilation or the HVR. We conclude that $1 \mathrm{~d}$, but not $30 \mathrm{~min}$, of $60 \% \mathrm{O}_{2}$ augments the HVR of neonatal rats and that production of the superoxide anion does not contribute to this plasticity.
\end{abstract}

\section{Keywords}

control of breathing; hypoxia; plasticity; reactive oxygen species; superoxide anion

\section{Introduction}

Chronic hyperoxia $\left(30-60 \% \mathrm{O}_{2}\right)$ for the first 1-4 postnatal weeks causes a long-lasting reduction in the hypoxic ventilatory response (HVR) in rats, primarily by impairing carotid body development (Ling et al., 1997; Bavis, 2005). In addition to reducing carotid body size and the number of chemoafferent axons in the carotid sinus nerve (Erickson et al., 1998; Wang \& Bisgard, 2005), hyperoxia progressively diminishes $\mathrm{O}_{2}$ sensitivity of the carotid body chemoreceptors (Donnelly et al., 2005, 2009). In a recent study by Donnelly and colleagues (2009), neonatal rats were exposed to $60 \% \mathrm{O}_{2}$ for up to two weeks beginning at 7 days of age (P7). Carotid body $\mathrm{O}_{2}$ sensitivity was reduced by P12 (i.e., after $5 \mathrm{~d}$ in hyperoxia) and remained low throughout the remainder of the hyperoxic exposure. There was, however, an unexpected increase in $\mathrm{O}_{2}$ sensitivity at $\mathrm{P} 8$ (i.e., after $1 \mathrm{~d}$ in hyperoxia). Specifically, in vitro single-unit chemoafferent activity and glomus cell intracellular $\mathrm{Ca}^{2+}$ responses to hypoxia were greatly enhanced upon exposure to severe hypoxia (Donnelly et al., 2009). The primary objective of the present study, therefore, was to determine whether

\footnotetext{
"Corresponding author: Ryan W. Bavis, Ph.D., Department of Biology, Bates College, 44 Campus Ave., Carnegie Science Hall, Lewiston, ME 04240 USA, Phone: 207-786-8269, Fax: 207-786-8334, rbavis@bates.edu.

Publisher's Disclaimer: This is a PDF file of an unedited manuscript that has been accepted for publication. As a service to our customers we are providing this early version of the manuscript. The manuscript will undergo copyediting, typesetting, and review of the resulting proof before it is published in its final citable form. Please note that during the production process errors may be discovered which could affect the content, and all legal disclaimers that apply to the journal pertain.
} 
the enhanced carotid body response to hypoxia following a $1 \mathrm{~d}$ exposure to moderate hyperoxia would cause a corresponding increase in the acute HVR in the intact animal.

The cellular pathways responsible for hyperoxia-induced potentiation of carotid body sensitivity are not known. Hyperoxia has a variety of excitatory effects on respiratory control in adult mammals, including hyperoxic hyperventilation (i.e., increased ventilation during a sustained exposure to hyperoxia) (Cragg et al., 1986, Becker et al., 1996), increased excitability of brainstem neurons linked to respiratory control (Mulkey et al., 2003), and glutamate- and nitric oxide (NO)-dependent potentiation of the HVR (Honda et al., 1996; Gozal, 1998; Pokorski et al., 2005). In each of these cases, however, the excitatory effects of hyperoxia (often $\geq 100 \%$ inspired $\mathrm{O}_{2}$ ) are believed to occur within the CNS, not the carotid body (Gozal, 1998; Dean et al., 2004). Interestingly, Peng and colleagues (2004) found that neonatal rats (P2) previously exposed to intermittent hypoxia $\left(15 \mathrm{~s}\right.$ of $5 \% \mathrm{O}_{2}$ separated by 5 min of $21 \% \mathrm{O}_{2}$ ) for 16 hours exhibit greater carotid body $\mathrm{O}_{2}$ sensitivity (i.e., increased single-unit chemoafferent responses to hypoxia in vitro) and augmented HVR. Longer periods of intermittent hypoxia ( $10 \mathrm{~d}$ ) have a similar effect on carotid body $\mathrm{O}_{2}$ sensitivity in neonatal rats (Pawar et al., 2008, 2009), and these effects are completely blocked by daily administration of the antioxidant drug manganese (III) tetrakis (1-methyl-4-pyridyl) porphyrin pentachloride (MnTMPyP), a potent, membrane-permeable superoxide anion $\left(\mathrm{O}_{2}{ }^{--}\right)$scavenger (Pawar et al., 2009). Like intermittent hypoxia, hyperoxia increases the production of $\mathrm{O}_{2}{ }^{--}$and other reactive oxygen species (Jamieson et al., 1986; Fabian et al., 2004; D'Agostino et al., 2007), even at moderate inspired $\mathrm{O}_{2}$ levels (e.g., 50-70\% $\mathrm{O}_{2}$; Brueckl et al., 2006). Thus, increased $\mathrm{O}_{2}{ }^{--}$production is one potential mechanism by which hyperoxia might enhance carotid body $\mathrm{O}_{2}$ sensitivity and the acute HVR. To test this hypothesis, we attempted to block hyperoxia-induced potentiation of the HVR using MnTMPyP.

\section{Methods}

\subsection{Experimental design}

Experiments were conducted on neonatal Sprague-Dawley rats (SAS SD, Charles River Laboratories, Wilmington, MA USA). Rats were born and raised with their mothers under standard conditions (12:12 light cycle, food and water ad libitum) until studied at P7-P8. All experimental procedures were approved by the Animal Care and Use Committee at Bates College.

In the first experiment, individual P7 rats (either sex) from ten litters received intaperitoneal injections of the antioxidant drug MnTMPyP pentachloride (5 mg ml${ }^{-1}$ in saline; Alexis Biochemicals, San Diego, CA USA) or an equal volume of vehicle (0.9\% saline; Phoenix Pharmaceutical, St. Joseph, MO USA). Each pup was injected with $0.01 \mathrm{ml}$ per $10 \mathrm{~g}$ body mass (i.e., $0.01 \mathrm{ml}$ for $0-10.0 \mathrm{~g}, 0.02 \mathrm{ml}$ for 10.1-20.0 g, etc.); thus, MnTMPyP pups received $5-10 \mathrm{mg} \mathrm{kg}^{-1}$ of the drug depending on their mass, equal to or exceeding the effective dosage used for rats in previous studies (e.g., Pawar et al., 2009). Five of these litters ("Hyperoxia") were then placed into an environmental chamber maintained at $60 \% \mathrm{O}_{2}$ $\left(\mathrm{CO}_{2}<0.4 \%\right)$ for approximately $1 \mathrm{~d}(23-28 \mathrm{~h})$. The remaining five litters ("Control") were placed into an environmental chamber maintained at $21 \% \mathrm{O}_{2}\left(\mathrm{CO}_{2}<0.4 \%\right)$ for the same time period. An additional group of rats was prepared at a later date to determine the effect of a supplemental dose of MnTMPyP. All pups in this group were injected with MnTMPyP and placed into environmental chambers flushed with $60 \% \mathrm{O}_{2}$ (2 litters) or $21 \% \mathrm{O}_{2}(3$ litters) as described above, but individuals received a second injection of the drug (5-10 mg $\mathrm{kg}^{-1}$, i.p.) $12 \mathrm{~h}$ after the initial dose was administered; in the following sections, rats that received this booster injection are indicated by "MnTMPyP $\times 2$ ". 
In a second experiment, three additional litters of rats were used to study the respiratory effects of a shorter hyperoxic exposure; no drugs were administered to these rats. P7-8 rats (either sex) from these litters were placed individually into a $600 \mathrm{ml}$ acrylic chamber flushed with gas containing either $60 \% \mathrm{O}_{2}$ ("Hyperoxia") or $21 \% \mathrm{O}_{2}$ ("Control") for $30 \mathrm{~min}$ (flow rate $=21 \mathrm{~min}^{-1}$ ). Since the rats were separated from the rest of their litter during this period, a water bath was used to warm the chamber to $\sim 34^{\circ} \mathrm{C}$ (i.e., within the neonatal rat thermoneutral zone; Malik \& Fewell, 2003) throughout the exposure.

Individual rats were removed from their respective chambers after $23-28 \mathrm{~h}$ (experiment 1 ) or $30 \mathrm{~min}$ (experiment 2 ) and immediately transferred to a plethysmograph for ventilation measurements. The number of individuals studied in each treatment group ranged from 1018 ; specific sample sizes are reported in the figure legends.

\subsection{Ventilation measurements}

Ventilation measurements were made using a customized head-body plethysmograph. The plethysmograph consisted of two acrylic cylindrical chambers: a head chamber $(4.75 \mathrm{~cm} \mathrm{ID;}$ $\sim 70 \mathrm{ml}$ ) through which test gases flowed and a body chamber (3.1 cm ID; internal volume was adjusted using modeling clay to limit the backward movement of the animal). A flexible collar made from layers of latex film ( $\sim 0.15 \mathrm{~mm}$ thick) and Parafilm (Pechiney Plastic Packaging, Menaha, WI USA) was fitted around the neck of the rat, thereby isolating the head and body compartments; a layer of petroleum jelly was applied around the rat's neck to prevent gas leaks. The body chamber contained a T-type thermocouple probe (IT-18, Physitemp Instruments, Clifton, NJ USA) to monitor air temperature as well as ports connected to a pneumotach (MLT1L, ADInstruments, Colorado Springs, CO USA) and a calibration syringe. The pneumotach was connected to a differential pressure transducer (ML141, ADInstruments, Colorado Springs, CO USA) to monitor respiratory airflows; the pneumotach was calibrated at the start of each experiment using a $0.5 \mathrm{ml}$ injection of air. Respiratory airflows and chamber temperature were recorded continuously to a computer at a sampling rate of $1000 \mathrm{~Hz}$ (PowerLab 8SP and LabChart 6 software, ADInstruments, Colorado Springs, CO USA). Respiratory airflows were integrated and digitally filtered (high-pass, $0.1 \mathrm{~Hz}$ ) to obtain respiratory volumes.

The plethysmograph was situated in an incubator so that the air temperature in the body chamber could be maintained at $32-34^{\circ} \mathrm{C}$ (i.e., within the thermoneutral zone of neonatal rats; Malik \& Fewell, 2003). Gas flow through the head chamber was set at $1500 \mathrm{ml} / \mathrm{min}$ using a gas mixing mass flow controller (MFC-4; Sable Systems, Las Vegas, NV USA) and valves (series 840; Sierra Instruments, Monterey, CA USA). After being weighed and sealed into the plethysmograph, the rat was exposed to $21 \% \mathrm{O}_{2}$ (balance $\mathrm{N}_{2}$ ) for at least $10 \mathrm{~min}$. Once the rat appeared calm (based on stability of the respiratory pattern), respiratory airflows were recorded under baseline conditions $\left(21 \% \mathrm{O}_{2}\right)$ and during an 8-min exposure to hypoxia $\left(12 \% \mathrm{O}_{2}\right)$.

\subsection{Data Analysis}

A breath-by-breath analysis of respiratory variables (tidal volume, respiratory frequency, and minute ventilation) was made for 30-45 s during baseline and for approximately $10 \mathrm{~s}$ at the end of the first minute of hypoxia (early phase of the HVR) and at the end of the eighth minute of hypoxia (late phase of the HVR), excluding obvious movement artifacts, sighs or vocalizations. The early phase of the HVR is generally thought to reflect activation of the peripheral chemoreflex, whereas changes in ventilation during longer exposures (i.e., late HVR) may be influenced by central respiratory depression and changes in metabolism (Teppema \& Dahan, 2010). If no differences were detected between treatment groups during the initial minute of hypoxia, respiratory variables were also calculated for the second 
minute of hypoxia (see Results sections 3.1 and 3.2). Hypoxic responses were expressed as a percentage increase from baseline.

In Experiment 1, statistical comparisons among groups were made using two-way analysis of variance [factor 1: hyperoxia treatment (Control, Hyperoxia); factor 2: drug treatment (Saline, MnTMPyP)]. Control and Hyperoxia groups that received supplemental MnTMPyP (i.e., MnTMPyP ×2) were compared using independent samples t-tests. In Experiment 2 (30 min gas exposures), Control and Hyperoxia groups were compared using independent samples t-tests. Differences were considered significant at $P<0.05$. All statistical tests were run using SigmaStat 3.11 (Systat Software, San Jose, CA, USA).

\section{Results}

\subsection{Experiment 1: $1 \mathrm{~d}$ exposure to hyperoxia}

Rat pups exposed to $60 \% \mathrm{O}_{2}$ for $23-28 \mathrm{~h}$ exhibited lower resting ventilation while breathing room air $\left(21 \% \mathrm{O}_{2}\right)$ than their age-matched controls (main effect for hyperoxia, $P<0.001$ ), and this did not vary with drug treatment (hyperoxia $\times$ drug, $P=0.14$ ) (Fig. 1A). Averaged across drug treatment groups (i.e., Saline and MnTMPyP), the minute ventilation for Hyperoxia rats was $25 \%$ lower than that of Control rats. This effect was primarily explained by a lower tidal volume in Hyperoxia rats (main effect for hyperoxia, $P=0.002$ ) (Fig. 1B), but there was also a trend toward lower respiratory frequency $(P=0.06)$ (Fig. 1C). Independent of $\mathrm{O}_{2}$ levels during the previous day, rats receiving MnTMPyP had a slightly lower baseline respiratory frequency compared to their saline-injected counterparts (main effect for drug, $P=0.02$ ) (Fig. 1C); no effects of MnTMPyP were detected for ventilation or tidal volume (i.e., drug and hyperoxia $\times$ drug, $P>0.05$ ).

Pretreatment with hyperoxia augmented both the early and late components of the acute HVR of neonatal rats (Fig. 2A), and MnTMPyP did not diminish this effect (hyperoxia $\times$ drug, $P=0.30$ and $P=0.54$ for early and late HVR, respectively). The increases in minute ventilation during $12 \% \mathrm{O}_{2}$ were greater in Hyperoxia rats than in Controls during the early and late HVR (main effect for hyperoxia, $P=0.002$ and $P=0.04$, respectively). Due to the lower baseline ventilation of Hyperoxia rats, however, the absolute value for minute ventilation achieved in hypoxia did not differ significantly between Hyperoxia and Control rats $(P=0.10$ and $P=0.08$ for early and late HVR, respectively). The greater HVR of Hyperoxia rats (as a percentage of baseline) primarily reflected an augmented tidal volume response (main effect for hyperoxia, $P=0.001$ and $P=0.02$ for early and late HVR, respectively) (Fig. 2B). Hyperoxia had no effect on the frequency response to acute hypoxia ( $P=0.87$ and $P=0.41$ for early and late HVR, respectively) (Fig. 2C).

Although MnTMPyP treatment did not influence the hyperoxia-induced potentiation of the HVR (i.e., no significant treatment $x$ drug interaction), this drug altered the acute HVR independent of the treatment group (i.e., main effect for drug). Specifically, rats that received a single dose of MnTMPyP tended to have reduced HVR compared to salineinjected rats (Fig. 2A), but this decrease was only significant during the late phase of the HVR (main effect for drug, $P=0.11$ and $P=0.03$ for early and late HVR, respectively). This reflected smaller increases in tidal volume during both the early and late phases of the HVR (main effect for drug, $P=0.04$ and $P=0.003$, respectively) (Fig. 2B). MnTMPyP had no effect on the frequency response to acute hypoxia $(P=0.76$ and $P=0.49$ for early and late HVR, respectively) (Fig. 2C).

To determine whether an additional dose of MnTMPyP would block the respiratory effects of the $1 \mathrm{~d}$ hyperoxia treatment, a subset of Control and Hyperoxia rats was administered a booster injection of the drug $12 \mathrm{~h}$ after the first injection (i.e., MnTMPyP $\times 2$ ). Baseline tidal 


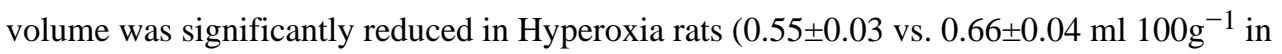
Control; $P=0.01)$ with no difference in respiratory frequency $(P=0.99)$. As a result, there was a marginally significant trend for Hyperoxia rats to exhibit lower minute ventilation under baseline conditions $(P=0.07)$ (Fig. 3A). There was also a non-significant trend for the HVR to be greater during the first minute of hypoxia in Hyperoxia rats compared to their Control group ( $P=0.18$ ) (Fig. 3B, left panel). Although we initially planned to use minute 1 to represent the early phase of the HVR, the early HVR appears to last several minutes in neonatal rats (Bavis et al., 2010). Therefore, to ensure that we did not overlook changes to the early HVR in this smaller sample of rats, we subsequently examined the HVR during the second minute of hypoxia as well. In this post hoc analysis, the early HVR of Hyperoxia rats was approximately double that of the Controls $(P<0.001)$ (Fig. 3B, right panel). The late HVR was also significantly greater in Hyperoxia rats $(P<0.001)$ (Fig. 3C). Accordingly, a second dose of MnTMPyP did not prevent hyperoxia-induced potentiation of the HVR.

\subsection{Experiment 2: 30 min exposure to hyperoxia}

The results from Experiment 1 indicate that $1 \mathrm{~d}$ of hyperoxia is sufficient to alter respiratory control in neonatal rats, but this raises the question of whether prolonged hyperoxia is necessary to elicit this plasticity. To determine whether an acute hyperoxic exposure might have the same effect, rats in this second experiment were exposed to only $30 \mathrm{~min}$ of $60 \% \mathrm{O}_{2}$ (or $21 \% \mathrm{O}_{2}$ as a control). Baseline minute ventilation did not differ between Hyperoxia and Control rats $(P=0.34)$ (Fig. 4A), nor did tidal volume or respiratory frequency (data not shown). There also were no differences detected between treatment groups for the early HVR (minute 1: $P=0.46$; minute 2: $P=0.49$ ) or late $\operatorname{HVR}(P=0.32)$ (Fig. $4 \mathrm{~B}, \mathrm{C}$ ).

\section{Discussion}

This study confirmed that a relatively brief ( $23-28 \mathrm{~h}$ ) period of moderate hyperoxia induces plasticity in the respiratory control system of neonatal rats. Specifically, rat pups exposed to approximately $1 \mathrm{~d}$ of $60 \% \mathrm{O}_{2}$ exhibited a lower tidal volume following return to room air and a greater ventilatory response to $12 \% \mathrm{O}_{2}$. The augmented HVR is consistent with the enhanced carotid body $\mathrm{O}_{2}$ sensitivity previously reported for rat pups exposed to a similar duration of hyperoxia (Donnelly et al., 2009). Ventilation measurements were made shortly after removal from hyperoxia (typically 10-30 $\mathrm{min}$ in normoxia prior to the onset of hypoxia, including time to establish baseline breathing), thus it is not known how long this plasticity persists. It is clear, however, that acute hyperoxic exposures ( $\leq 30 \mathrm{~min})$ do not produce comparable changes to the respiratory control of neonatal rats. Finally, contrary to our hypothesis, the superoxide scavenging drug MnTMPyP did not prevent this plasticity.

\subsection{Reduced normoxic ventilation following $1 \mathrm{~d}$ of hyperoxia}

After $1 \mathrm{~d}$ in $60 \% \mathrm{O}_{2}$, neonatal rats exhibited reduced tidal volumes while breathing room air and, as a result, generally exhibited reduced minute ventilation as well. The reduction in minute ventilation was not quite significant in the MnTMPyP $\times 2$ group $(P=0.07)$, but this likely reflects the relatively small sample sizes for this comparison $(n=12-13)$ rather than an effect of the drug per se since: (1) hyperoxia-treated rats had significantly lower tidal volumes and normal respiratory frequencies compared to their control group and (2) the average minute ventilation was $18 \%$ lower in hyperoxia-treated rats in the MnTMPyP $\times 2$ group, similar in magnitude to the $25 \%$ reduction in minute ventilation observed in hyperoxia-treated rats that received only a single injection of saline or MnTMPyP. Therefore, these data do not indicate a major role for $\mathrm{O}_{2}{ }^{--}$in the observed changes to eupneic breathing. 
We recently reported reduced tidal volume and minute ventilation in neonatal rats exposed to $4-7 \mathrm{~d}$ of $60 \% \mathrm{O}_{2}$ from birth (Bavis et al., 2010). It therefore appears that $1 \mathrm{~d}$ and $7 \mathrm{~d}$ hyperoxic exposures have qualitatively similar effects on normoxic breathing. In the earlier study, it was found that chronic hyperoxia also decreased normoxic $\mathrm{O}_{2}$ consumption (Bavis et al., 2010). Accordingly, lower baseline ventilation may reflect, at least in part, reduced metabolic demands in hyperoxia-treated rats. It is also possible that hyperoxia-treated rats experience diminished tonic drive from peripheral chemoreceptors. Although not specifically reported in the paper by Donnelly and colleagues (2009), baseline carotid chemoafferent neuron discharge rate was reduced in P8 rats after a 1-d exposure to hyperoxia ( $0.2 \pm 0.1$ vs. $1.3 \pm 0.4 \mathrm{~Hz}$ in age-matched controls; D.F. Donnelly \& R.W. Bavis, unpublished data). Chronic hyperoxia also causes degeneration of carotid chemoafferent neurons (Erickson et al., 1998), but whether this occurs in as little as one day remains to be determined.

\subsection{Augmented HVR following $1 \mathrm{~d}$ of hyperoxia}

The acute HVR was greater in neonatal rats subjected to $1 \mathrm{~d}$ of $60 \% \mathrm{O}_{2}$. This effect was apparent within the first 1-2 minutes of hypoxia (i.e., the early HVR), indicating increased activation of the peripheral chemoreflex; metabolism was not measured in this study, but it is unlikely that altered metabolic responses to hypoxia would influence the early phase of the HVR. Although we cannot rule out an additional CNS contribution to this plasticity, the most likely explanation for the augmented HVR is enhanced sensitivity of the carotid chemoreceptors themselves: in vitro carotid chemoafferent and glomus cell intracellular $\mathrm{Ca}^{2+}$ responses to hypoxia are enhanced after a similar duration of hyperoxia (Donnelly et al., 2009). Longer durations ( $>4$ d) of hyperoxia are known to diminish carotid body (Bisgard et al., 2003; Donnelly et al., 2005, 2009) and ventilatory responses to hypoxia (Ling et al., 1997; Bavis et al., 2010) which suggests that this excitatory plasticity is only transiently expressed and/or that it is subsequently obscured by other (inhibitory) forms of plasticity that develop more slowly.

Given the qualitatively similar effects of chronic intermittent hypoxia and $1 \mathrm{~d}$ of hyperoxia (i.e., increased carotid body and ventilatory responses to hypoxia) and the fact that both conditions stimulate the production of reactive oxygen species, we hypothesized that these forms of plasticity would share the same mechanistic pathways. In contrast to chronic intermittent hypoxia, however, there was no evidence that increased production of $\mathrm{O}_{2}{ }^{\cdot-}$ plays a significant role in the potentiation of the HVR (and presumably carotid body $\mathrm{O}_{2}$ sensitivity) after a $1 \mathrm{~d}$ hyperoxic exposure in neonatal rats. A single, daily injection of MnTMPyP is sufficient to abolish carotid body plasticity during chronic intermittent hypoxia in neonatal (Pawar et al., 2009) and adult (Peng \& Prabhakar, 2004) rats, but this treatment did not diminish the effects of hyperoxia on the acute HVR; this was also the case when rats received a supplemental dose of MnTMPyP halfway through the hyperoxic exposure. Importantly, systemic injection of MnTMPyP blocks $\mathrm{O}_{2}{ }^{--}$production in both peripheral and CNS tissues (e.g., Peng et al., 2006; Sharma et al., 2009), so it is unlikely that $\mathrm{O}_{2}{ }^{--}$contributes directly to any (as of yet undiscovered) central component to this plasticity either. However, we cannot completely exclude a role for reactive oxygen species, other than $\mathrm{O}_{2}{ }^{--}$, or reactive nitrogen species in this plasticity without administering a variety of antioxidant drugs.

It has been suggested that acute hyperoxia can enhance the acute HVR in adult mammals through an NO-dependent mechanism (Gozal, 1998; Pokorski et al., 2005). Specifically, conscious (Gozal, 1998) and anesthetized (Pokorski et al., 2005) adult rats exhibit augmented HVR after breathing $100 \% \mathrm{O}_{2}$ for only $10-15$ minutes. Although we did not observed a change in the HVR of neonatal rats exposed to $30 \mathrm{~min}$ of $60 \% \mathrm{O}_{2}$, it is possible that longer exposures are required to initiate this plasticity in neonates and/or when lower 
inspired $\mathrm{O}_{2}$ levels are used (i.e., 60 vs. $100 \% \mathrm{O}_{2}$ ). Gozal (1998) reported that selective inhibition of neuronal nitric oxide synthase (nNOS) completely abolishes the effect of $100 \%$ $\mathrm{O}_{2}$ on the HVR in adult rats. Since NO generally inhibits carotid body responses to hypoxia (Lahiri et al., 2006) but exerts excitatory effects on the HVR centrally, Gozal (1998) postulated that hyperoxia potentiates the acute HVR by increasing NO production in the brainstem. While we cannot rule out central effects of hyperoxia on the HVR of neonatal rats, Gozal's model does not explain the increased carotid body $\mathrm{O}_{2}$ sensitivity (Donnelly et al., 2009) that almost certainly contributes to the hyperoxia-induced potentiation of the HVR observed in the present study. Interestingly, Pokorski and colleagues (2005) found that inhibition of nNOS or combined inhibition of nNOS and glutamate receptors diminished, but did not eliminate, the effects of $100 \% \mathrm{O}_{2}$ exposure on the HVR of anesthetized, adult rats; the residual enhancement of the HVR could originate from peripheral chemoreceptors in this case. Likewise, it would be interesting to know whether there is a central, NOdependent component to the augmented HVR of neonatal rats after $1 \mathrm{~d}$ hyperoxia.

\subsection{MnTMPyP and the acute HVR}

Although MnTMPyP did not prevent hyperoxia-induced potentiation of the acute HVR, this drug did have an effect on respiratory control. MnTMPyP reduced the HVR in both normoxia-treated and hyperoxia-treated rats (i.e., independent of the level of $\mathrm{O}_{2}$ experienced during the preceding $23-28 \mathrm{~h}$ ), as shown by the significant main effect for the drug treatment in Figures 2A and 2B. Interestingly, a similar effect has been noted in anesthetized, adult rats. Phrenic nerve responses to acute hypoxia tended to be reduced in adult rats after acute administration of 5 or $10 \mathrm{mg} \mathrm{kg}^{-1}$ doses of MnTMPyP (MacFarlane \& Mitchell, 2008, their Fig. 2). Although this effect was not statistically significant when groups receiving the two doses were considered separately ( $n=8$ per group), the reduction is significant when these rats are pooled to increase statistical power $[77 \pm 9 \%$ increase in phrenic burst amplitude for MnTMPyP-treated rats vs. $120 \pm 29 \%$ increase for vehicle-treated controls, $P=0.04$ (independent samples t-test); P.M. MacFarlane \& G.S. Mitchell, personal communication]. Together, these observations suggest a role for $\mathrm{O}_{2}{ }^{--}$in the acute HVR of normal, untreated rats.

The role of ROS in $\mathrm{O}_{2}$ sensing at the carotid body continues to be debated (Lahiri et al., 2006; Gonzalez et al., 2007), so it is not clear whether MnTMPyP could directly interfere with this mechanism. Alternatively, Gonzalez and colleagues (2007) propose that superoxide dismutase mimetics such as MnTMPyP may increase NO levels (by limiting the reaction of $\mathrm{O}_{2}{ }^{--}$and $\mathrm{NO}$ to form peroxynitrite), thereby inhibiting carotid body activity. However, there is no evidence that repeated, systemic administration of MnTMPyP depresses subsequent in vitro carotid body activity in neonatal rats (Pawar et al., 2009). It is also possible that $\mathrm{O}_{2}{ }^{--}$or other reactive oxygen species normally contribute to regulation of the acute HVR downstream of the carotid chemoafferent neurons, or perhaps at other peripheral/central chemoreceptors (e.g., Dean, 2010).

\section{Conclusions}

We have shown that a $1 \mathrm{~d}$ exposure to moderate hyperoxia augments the acute HVR in neonatal rats. This is opposite of the effect produced by prolonged developmental hyperoxia (which blunts the HVR; Ling et al., 1997; Bavis, 2005; Bavis et al., 2010) but resembles the effect of brief (10-15 min) hyperoxia in adult humans (Honda et al., 1996) and rats (Gozal, 1998; Pokorski et al., 2005). These findings confirm that prevailing $\mathrm{O}_{2}$ levels, whether of short or long duration, can profoundly influence the respiratory control system. The diversity of this plasticity, however, emphasizes that the respiratory phenotype may reflect simultaneous changes in multiple cellular and/or anatomical pathways. Although the present data did not reveal a role for hyperoxia-induced production of $\mathrm{O}_{2}{ }^{--}$in this plasticity, future 
studies should consider the potential involvement of other reactive oxygen and/or nitrogen species.

\section{Acknowledgments}

The authors thank Nelish Pradhan and Elizabeth Dmitrieff for technical assistance and Laurie McConnell for assistance with data entry. This work was supported by National Institutes of Health grant HL-083972.

\section{References}

Bavis RW. Developmental plasticity of the hypoxic ventilatory response after perinatal hyperoxia and hypoxia. Respir Physiol Neurobiol 2005;149:287-299. [PubMed: 16203217]

Bavis RW, Young KM, Barry KJ, Boller MR, Kim E, Klein PM, Ovrutsky AR, Rampersad DA. Chronic hyperoxia alters the early and late phases of the hypoxic ventilatory response in neonatal rats. J Appl Physiol 2010;109:796-803. [PubMed: 20576840]

Becker H, Polo O, McNamara SG, Berthon-Jones M, Sullivan CE. Effect of different levels of hyperoxia on breathing in healthy subjects. J Appl Physiol 1996;81:1683-1690. [PubMed: 8904587]

Bisgard GE, Olson EB Jr, Wang ZY, Bavis RW, Fuller DD, Mitchell GS. Adult carotid chemoafferent responses to hypoxia after 1, 2, and 4 wk of postnatal hyperoxia. J Appl Physiol 2003;95:946-952. [PubMed: 12909596]

Brueckl C, Kaestle S, Kerem A, Habazettl H, Krombach F, Kuppe H, Kuebler WM. Hyperoxiainduced reactive oxygen species formation in pulmonary capillary endothelial cells in situ. Am J Respir Cell Mol Biol 2006;34:453-463. [PubMed: 16357365]

Cragg PA, Drysdale DB, Hamilton JH. Ventilation in intact and glossopharyngeal nerve sectioned anaesthetized rats exposed to oxygen at high pressure. J Physiol 1986;370:489-499. [PubMed: 3958984]

D'Agostino DP, Putnam RW, Dean JB. Superoxide $\left(\mathrm{O}_{2}{ }^{\bullet-}\right)$ production in CA1 neurons of rat hippocampal slices exposed to graded levels of oxygen. J Neurophysiol 2007;98:1030-1041. [PubMed: 17553943]

Dean JB. Hypercapnia causes cellular oxidation and nitrosation in addition to acidosis: implications for $\mathrm{CO}_{2}$ chemoreceptor function and dysfunction. J Appl Physiol 2010;108:1786-1795. [PubMed: 20150563]

Dean JB, Mulkey DK, Henderson RA III, Potter SJ, Putnam RW. Hyperoxia, reactive oxygen species, and hyperventilation: oxygen sensitivity of brainstem neurons. J Appl Physiol 2004;96:784-791. [PubMed: 14715688]

Donnelly DF, Kim I, Carle C, Carroll JL. Perinatal hyperoxia for 14 days increases nerve conduction time and the acute unitary response to hypoxia of rat carotid body chemoreceptors. J Appl Physiol 2005;99:114-119. [PubMed: 15731397]

Donnelly DF, Bavis RW, Kim I, Dbouk HA, Carroll JL. Time-course of alterations in pre- and postsynaptic chemoreceptor function during developmental hyperoxia. Respir Physiol Neurobiol 2009;168:189-197. [PubMed: 19465165]

Erickson JT, Mayer C, Jawa A, Ling L, Olson EB Jr, Vidruk EH, Mitchell GS, Katz DM. Chemoafferent degeneration and carotid body hypoplasia following chronic hyperoxia in newborn rats. J Physiol 1998;509:519-526. [PubMed: 9575300]

Fabian RH, Oerez-Polo JR, Kent TA. Extracellular superoxide concentration increases following cerebral hypoxia but does not affect cerebral blood flow. Int J Dev Neurosci 2004;22:225-230. [PubMed: 15245758]

Gonzalez C, Agapito MT, Rocher A, Gonzalez-Martin MC, Vega-Agapito V, Gomez-Niño A, Rigual R, Castañeda J, Obeso A. Chemoreception in the context of the general biology of ROS. Respir Physiol Neurobiol 2007;157:30-44. [PubMed: 17331812]

Gozal D. Potentiation of hypoxic ventilatory response by hyperoxia in the conscious rat: putative role of nitric oxide. J Appl Physiol 1998;85:129-132. [PubMed: 9655765] 
Honda Y, Tani H, Masuda A, Kobayashi T, Nishino T, Kimura H, Masuyama S, Kuriyama T. Effect of prior $\mathrm{O}_{2}$ breathing on ventilatory response to sustained isocapnic hypoxia in adult humans. $\mathrm{J}$ Appl Physiol 1996;81:1627-1632. [PubMed: 8904579]

Jamieson D, Chance B, Cadenas E, Boveris A. The relation of free radical production to hyperoxia. Ann Rev Physiol 1986;48:703-719. [PubMed: 3010832]

Lahiri S, Roy A, Baby SM, Hoshi T, Semenza GL, Prabhakar NR. Oxygen sensing in the body. Prog Biophys Mol Biol 2006;91:249-286. [PubMed: 16137743]

Ling L, Olson EB Jr, Vidruk EH, Mitchell GS. Developmental plasticity of the hypoxic ventilatory response. Respir Physiol 1997;110:261-268. [PubMed: 9407619]

MacFarlane PM, Mitchell GS. Respiratory long-term facilitation following intermittent hypoxia requires reactive oxygen species formation. Neuroscience 2008;152:189-197. [PubMed: 18207649]

Malik SS, Fewell JE. Thermoregulation in rats during early postnatal maturation: importance of nitric oxide. Am J Physiol Regul Integr Comp Physiol 2003;285:R1366-1372. [PubMed: 14615402]

Mulkey DK, Henderson RA III, Punam RW, Dean JB. Hyperbaric oxygen and chemical oxidants stimulate $\mathrm{CO}_{2} / \mathrm{H}^{+}$-sensitive beurons in rat brain stem slices. J Appl Physiol 2003;95:910-921. [PubMed: 12704094]

Pawar A, Peng YJ, Jacono FJ, Prabhakar NR. Comparative analysis of neonatal and adult rat carotid body responses to chronic intermittent hypoxia. J Appl Physiol 2008;104:1287-1294. [PubMed: 18187605]

Pawar A, Nanduri J, Yuan G, Khan SA, Wang N, Kumar GK, Prabhakar NR. Reactive oxygen species-dependent endothelin signaling is required for augmented hypoxic sensory response of the neonatal carotid body by intermittent hypoxia. Am J Physiol Regul Integr Comp Physiol 2009;296:R735-R742. [PubMed: 19109370]

Peng YJ, Prabhakar NR. Effect of two paradigms of chronic intermittent hypoxia on carotid body sensory activity. J Appl Physiol 2004;96:1236-1242. [PubMed: 14660510]

Peng YJ, Rennison J, Prabhakar NR. Intermittent hypoxia augments carotid body and ventilatory response to hypoxia in neonatal rat pups. J Appl Physiol 2004;97:2020-2025. [PubMed: 15258129]

Peng YJ, Yuan G, Ramakrishnan D, Sharma SD, Bosch-Marce M, Kumar GK, Semenza GL, Prabhakar NR. Heterozygous HIF-1 $\alpha$ deficiency impairs carotid body-mediated systemic responses and reactive oxygen species generation in mice exposed to intermittent hypoxia. $\mathrm{J}$ Physiol 2006;577:705-716. [PubMed: 16973705]

Pokorski M, Kolesnikova E, Marczak M, Budzinska K. Neurotransmitter mechanisms in the enhancement of the hypoxic ventilatory response by antecedent hyperoxia in the anesthetized rat. $\mathrm{J}$ Physiol Pharmacol 2005;56:433-446. [PubMed: 16204765]

Sharma SD, Raghuraman G, Lee MS, Prabhakar NR, Kumar GK. Intermittent hypoxia activates peptidylglycine $\alpha$-amidating monooxygenase in rat brain stem via reactive oxygen speciesmediated proteolytic processing. J Appl Physiol 2009;106:12-19. [PubMed: 18818385]

Teppema LJ, Dahan A. The ventilatory response to hypoxia in mammals: mechanisms, measurement, and analysis. Physiol Rev 2010;90:675-754. [PubMed: 20393196]

Wang ZY, Bisgard GE. Postnatal growth of the carotid body. Respir Physiol Neurobiol 2005;149:181190. [PubMed: 15914098] 

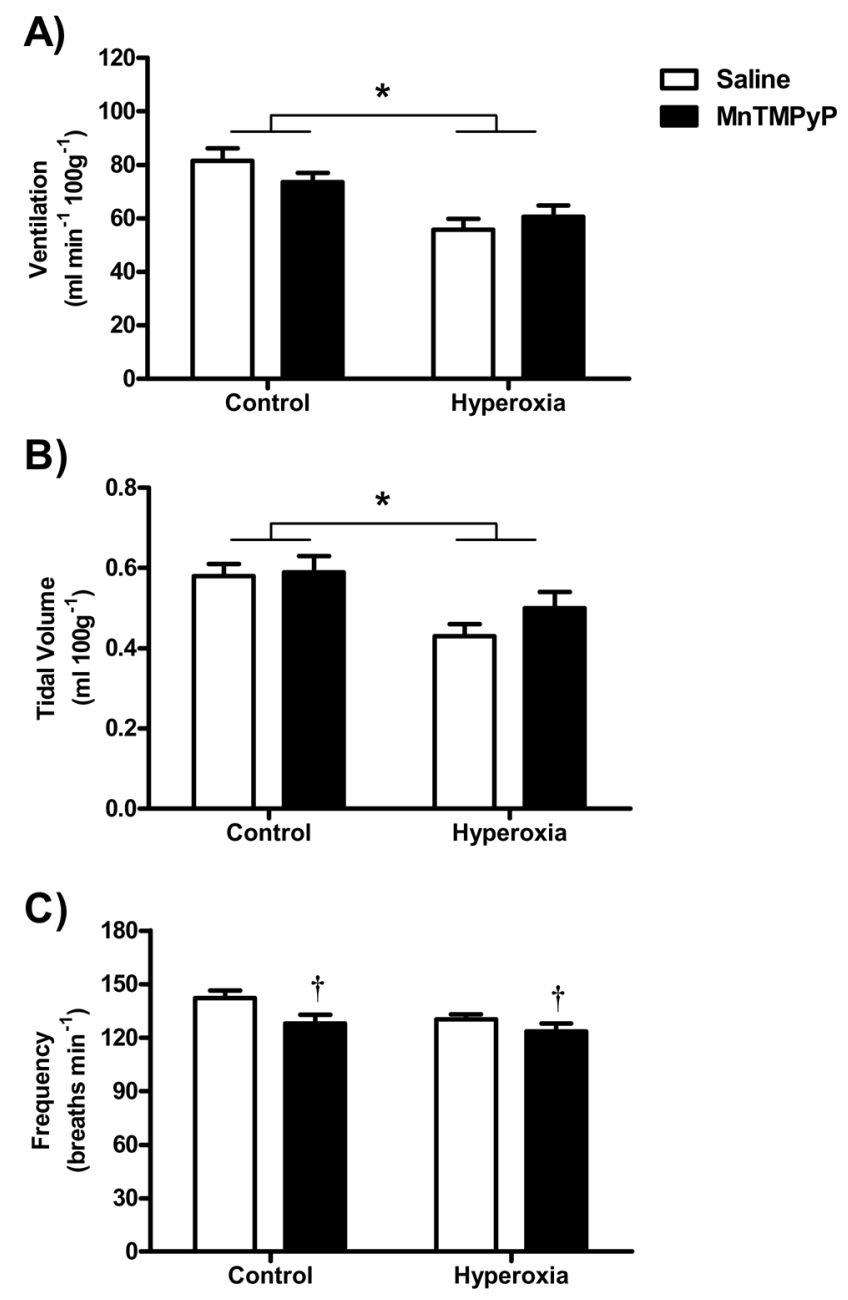

Fig. 1.

(A) Baseline $\left(21 \% \mathrm{O}_{2}\right)$ minute ventilation, $(\mathrm{B})$ tidal volume, and $(\mathrm{C})$ respiratory frequency for neonatal rats exposed to $21 \% \mathrm{O}_{2}$ (Control) or $60 \% \mathrm{O}_{2}$ (Hyperoxia) for the preceding 2328 hours. Individuals were injected with saline ( $n=15$ Control, 12 Hyperoxia) or the antioxidant drug MnTMPyP (5-10 $\mathrm{mg} \mathrm{kg}^{-1}$, i.p.) (n=11 Control, 10 Hyperoxia). Values are mean \pm SEM. Symbols denote significant $(P<0.05)$ main effects for hyperoxia treatment $(*)$ or drug treatment $(\dagger)$ based on a 2 -way ANOVA. 


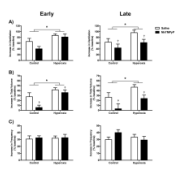

Fig. 2.

Ventilatory responses to $12 \% \mathrm{O}_{2}$ for neonatal rats exposed to $21 \% \mathrm{O}_{2}$ (Control) or $60 \% \mathrm{O}_{2}$ (Hyperoxia) for the preceding 23-28 hours. Individuals were injected with saline or the antioxidant drug MnTMPyP (5-10 $\mathrm{mg} \mathrm{kg}^{-1}$, i.p.). Increases in (A) minute ventilation, (B) tidal volume, and $(\mathrm{C})$ respiratory frequency are presented as a percentage of baseline during the early (minute 1) or late (minute 8 ) phases of the response. Values are mean \pm SEM. Sample sizes and symbols for statistical comparisons are the same as in Fig. 1. 


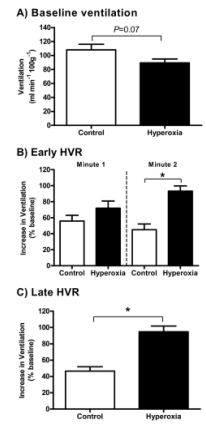

Fig. 3.

(A) Baseline $\left(21 \% \mathrm{O}_{2}\right)$ minute ventilation and the (B) early (minutes 1 and 2$)$ and (C) late (minute 8) ventilatory responses to $12 \% \mathrm{O}_{2}$ for neonatal rats exposed to $21 \% \mathrm{O}_{2}$ (Control, $\mathrm{n}=12$ ) or $60 \% \mathrm{O}_{2}$ (Hyperoxia, $\mathrm{n}=13$ ) for the preceding 23-28 hours. All rats were administered 5-10 $\mathrm{mg} \mathrm{kg}^{-1}$ (i.p.) MnTMPyP twice, once at the start of the exposure and once $12 \mathrm{~h}$ into the exposure (i.e., MnTMPyP $\times 2$ ). Values are mean \pm SEM. $*$ denotes significantly different groups $(P<0.05)$. 


\section{A) Baseline ventilation}

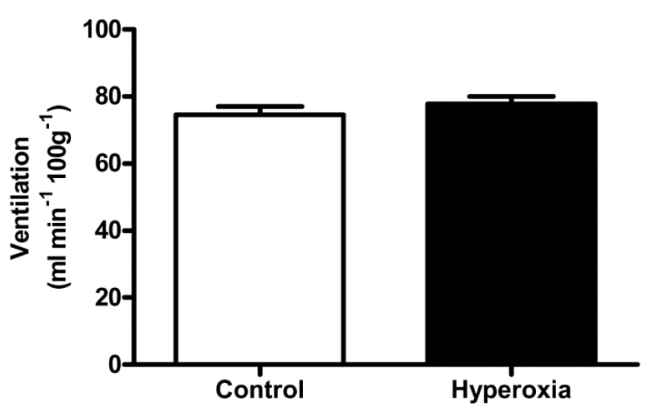

\section{B) Early HVR}

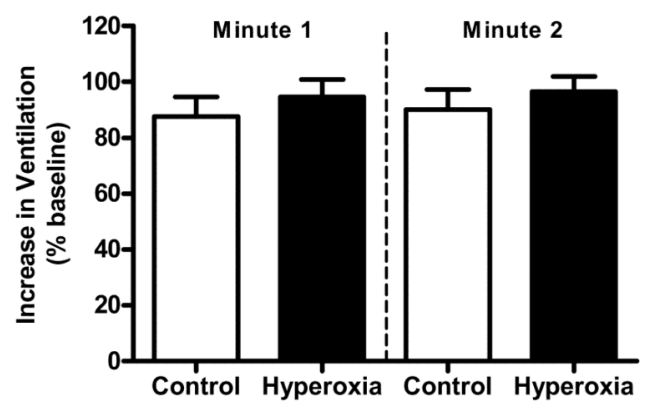

\section{C) Late HVR}

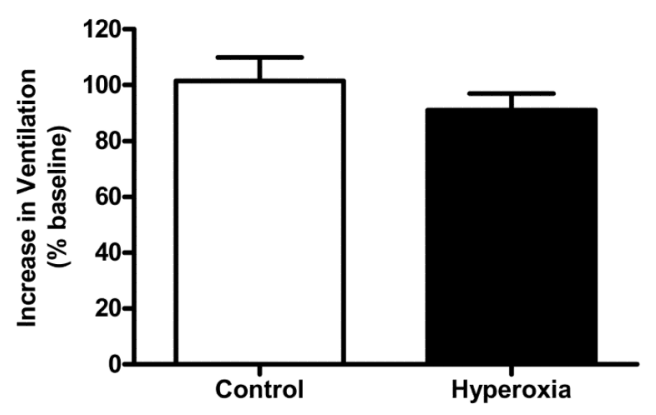

Fig. 4.

(A) Baseline $\left(21 \% \mathrm{O}_{2}\right)$ minute ventilation and the (B) early (minutes 1 and 2$)$ and (C) late (minute 8) ventilatory responses to $12 \% \mathrm{O}_{2}$ for neonatal rats exposed to $21 \% \mathrm{O}_{2}$ (Control, $\mathrm{n}=16$ ) or $60 \% \mathrm{O}_{2}$ (Hyperoxia, $\mathrm{n}=18$ ) for the preceding $30 \mathrm{~min}$. Values are mean \pm SEM. No significant differences were detected between groups. 